\title{
SISTEM INFORMASI MANAJEMEN PERSEDIAAN OBAT PADA APOTIK KIMIA FARMA KOTA TERNATE
}

\section{INFORMATION SYSTEM OF MEDICINE INVENTORY MANAGEMENT IN PHARMACY KIMIA FARMA TERNATE CITY}

\author{
Fariani Arifin $^{1}$, Muharto ${ }^{2}$ \\ Program Studi Manajemen Informatika \\ Politeknik Sains dan Teknologi Wiratama Maluku Utara \\ fariani_arifin@gmail.com
}

\begin{abstract}
Abstrak
Penelitian ini bertujuan untuk merancang sistem informasi Manajemen Persediaan obat pada Apotik kimia farma kota Ternate. Analisis sistem menggunakan Driven Model, dengan pendekatan terstruktur. Sedangkan pengembangan system mengacu pada model Waterfall. Hasil perancangan dan pengujian sistem dapat mempermudah dan mempercepat proses kerja Admin dan User dalam mengelola data obat dan transaksi obat pada Apotik Kimia Farma, Selain itu, mempermudah pemilik untuk melihat laporan secara cepat pada sistem dimana saja melalui jaringan internet. Serta meningkatkan kinerja karyawan dalam proses pembuatan laporan transaksi dan data stok obat
\end{abstract}

Kata kunci: Manajemen, Sistem Informasi, Website, Apotik, Kimia Farma.

\begin{abstract}
This study aims to design a management information system for drug supplies in pharmacy chemistry pharmacies in Ternate. System analysis used Driven Model, with a structured approach. While the development of the system refers to the Waterfall model. The results of designing and testing the system can simplify and speed up the Admin and User work processes in managing drug data and drug transactions at Kimia Farma Pharmacy, In addition, it is easier for owners to see reports quickly on a system anywhere via the internet network. As well as improving employee performance in the process of making transaction reports and drug stock data
\end{abstract}

Keywords: Management, Information System, Website, Pharmacy, Kimia Farma.

\section{PENDAHULUAN}

Teknologi informasi tidak dapat dianggap sebagai alat pendukung tetapi telah menjadi kebutuhan strategis untuk membangun infrastruktur teknologi informasi layanan kesehatan yang terintegrasi yang dapat meningkatkan pelayanan dan mengurangi kesalahankesalahan medis (Mantzana dan Vance Wilson, 2007). Perkembangan teknologi informasi ini mendapat perhatian serius baik pihak pemerintah mapun pihak industry. Dalam dunia medis sangat dibutuhkan penggunaan teknologi informasi sebagai mana ungkapan Tung (2008) bahwa sektor medis adalah sektor yang padat modal, padat karya dan padat informasi, sehingga pertukaran informasi yang sangat besar telah menarik perhatian para pelaku industri kesehatan. 
Di dalam mendukung arus pelayanan medis baik di rumah sakit maupun masyarakat umum sangat diperlukan system informasi. Pekerjaan kefarmasian yang berkaitan dengan proses distribusi atau penyaluran sediaan farmasi pada fasilitas distribusi atau penyaluran sediaan farmasi wajib dicatat oleh tenaga kefarmasian sesuai dengan tugas dan fungsinya. Tenaga Kefarmasian dalam melakukan pekerjaan Kefarmasian harus mengikuti perkembangan ilmu pengetahuan dan teknologi di bidang distribusi atau penyaluran (Sumber: PP Nomor 51, 2009).

Apotek merupakan suatu tempat pelayanan produk maupun jasa kefarmasian atau obat-obatan terhadap masyarakat. Apotek merupakan salah satu usaha yang termasuk di bidang perdagangan yang juga memerlukan adanya sebuah sistem pengolahan data untuk dapat mempermudah dan memperlancar kinerjanya. Masih cukup banyak Apotek yang memberdayakan tenaga manusia dalam mengolah data obat demi memperlancar usahanya, hal tersebut juga masih diterapkan yaitu salah satunya pada Apotek Kimia Farma.

Apotek Kimia Farma Bastiong merupakan salah satu dari beberapa cabang Apotek Kimia Farma yang ada di kota Ternate yang memiliki beberapa masalah yang dihadapi dalam manajemen persediaan obat yang diterapkan oleh Apotik Kimia Farma. Manajemen persediaan yang terpisah-pisah dan masih manual (ratusan item obat belum dipantau secara up to date), pencatatan stok yang dilakukan petugas masih manual, sehingga rawan terjadinya human error pada akhirnya berdampak terhadap ketidakakuratan informasi yang tersedia. Mengingat begitu banyaknya data yang harus dicatat, maka pencatatan secara manual tentu saja akan memakan waktu serta rawan terjadi kesalahan dalam menginput data dan pengecekkan data, sehingga perlu adanya sistem yang terkomputerisasi yang dapat membantu petugas dalam mengelola data obat tersebut serta mempermudah pimpinan dalam melihat laporan-laporan yang dibutuhkan dengan cepat dan tepat. Berdasarkan permasalahan tersebut, maka diperlukan perancangan sistem informasi manajemen persediaan obat pada Apotik Kimia Farma Kota Ternate.

\section{Rumusan Masalah}

Permasalahan dalam penelitian ini dirumuskan sebagai berikut: "Bagaimana Merancang Sistem Informasi Manajemen Persediaan Obat Pada Apotik Kimia Farma Kota Ternate?" Penelitian ini dibatasi pada perancangan pengelolaan dan persediaan data obat dengan menggunakan bahasa Pemrograman html, php, Mysql. Dengan demikian, penelitian ini bertujuan untuk merancang sistem informasi Manajemen Persediaan obat pada Apotik kimia farma kota ternate.

\section{LANDASAN TEORI Sistem Informasi}

Sistem adalah sebagai sekumpulan prosedur yang saling berkaitan dan saling berhubung untuk melakukan suatu tugas bersama-sama (Pratama, 2014:7). Darmawan (2013:4) sistem adalah sekelompok elemen-elemen yang terintegrasi dengan tujuan yang sama untuk mencapai tujuan.

Kusrini (dalam Taufiq, 2013:87) menjelaskan bahwa Informasi merupakan hasil olahan data, di mana data tersebut sudah diproses dan diinterprestasikan menjadi sesuatu yang bermakna untuk 
pengambilan keputusan. Informasi juga diartikan sebagai himpunan dari data yang relevan dengan satu atau beberapa orang dalam suatu waktu. Kualitas suatu informasi tergantung dari 4 hal, yaitu: 1) Akurat, berarti informasi harus jelas; 2) Tepat waktu, berarti informasi yang tiba pada konsumen tidak terlambat; 3) Bermanfaat, berarti dalam informasi yang diterima memiliki kegunaan bagi konsumen; 4) Biaya, berarti dalam memperoleh informasi terebut tanpa mengeluarkan biaya yang banyak.

Sistem informasi adalah sistem di dalam satuan organisasi yang mempertemukan kebutuhan pengolahan transaksi harian, mendukung operasi, bersifat manajerial dan kegiatan strategi dari suatu organisasi dan menyediakan pihak luar tertentu dengan laporan-laporan yang di perlukan (Jogiyanto, 2005:23). Menurut Sutabri (2005:14) sistem informasi adalah kombinasi antara prosedur kerja, iformasi, manusia dan teknologi informasi yang diorganisasikan untuk mencapai tujuan dalam sebuah organisasi.

Menurut Kadir (2003) suatu sistem informasi terdapat komponen-komponen seperti: 1) Perangkat keras (Hardware): mencakup peranti-peranti fisik seperti komputer dan printer; 2) Perangkat lunak (Software) atau program: sekumpulan instruksi yang memungkinkan perangkat keras untuk dapat memproses data; 3) Prosedur: sekumpulan aturan yang di pakai untuk mewujudkan pemrosesan data dan pembangkitkan keluaran yang di kehendaki; 4) Orang: semua pihak yang bertanggung jawab dalam pengembangan sistem informasi, pemrosesan, dan penggunaan keluaran sistem informasi; 5) Basis Data (Database): sekumpulan tabel, hubungan, dan lain-lain yang berkaitan dengan penyimpanan data: 6) Jaringan komputer dan komunikasi data: sistem penghubung yang memungkinkan sesumber (resources) dipakai secara bersama atau diakses oleh sejumpah pemakai.

\section{Sistem Informasi Manajemen}

Sistem Informasi Manajemen adalah suatu sistem yang dirancang untuk menyajikan informasi pilihan yang berorientasi kepada keputusan yang diperlukan oleh manajemen guna merencanakan, mengawasi, dan menilai aktifitas organisasi (Lestari, dkk, 2011). Sistem informasi manajemen (manajement information system atau sering dikenal dengan singkatannya MIS) merupakan penerapan sistem informasi di dalam organisasi untuk mendukung informasiinformasi yang dibutuhkan oleh semua tingkatan manajemen. SIM (sistem informasi manajemen) dapat didefenisikan sebagai kumpulan dari interaksi sistemsistem informasi yang bertanggung jawab mengumpulkan dan mengolah data untuk menyediakan informasi yang berguna untuk semua tingkatan manajemen di dalam kegiatan perencanaan dan pengendalian. Secara teori, komputer tidak harus digunakan didalam SIM, tetapi kenyataannya tidaklah mungkin SIM yang komplek dapat berfungsi tanpa melibatkan elemen komputer. Lebih lanjut, bahwa SIM selalu berhubungan dengan pengolahan informasi yang menyebutkan pada komputer (computer-based information processing). Pangestu (2007) menjelaskan bahwa SIM merupakan kumpulan dari sistem-sistem informasi. SIM tergantung dari besar kecilnya organisasi dapat terdiri dari sistem-sistem informasi seperti: 1) Sistem informasi akuntansi (accounting information 
system); 2) menyediakan informasi dari transaksi keuangan; Sistem informasi pemasaran (marketing information system), menyediakan informasi untuk penjualan, promosi penjualan, kegiatankegiatan pemasaran, kegiatan-kegiatan penelitian pasar dan lain sebagainya yang berhubungan dengan pemasaran; Sistem informasi manajemen persediaan (inventory management information system): 3) Sistem informasi personalia (personnel information systems); 4) Sistem informasi distribusi (distribution information systems); 5) Sistem informasi pembelian (purchasing information systems); 6) Sistem informasi kekayaan (treasury information systems); 7) Sistem informasi analisis kredit (credit analiysis information systems); 8) Sistem informasi penelitian dan pengembangan (research and development information systems); 9) Sistem informasi teknik (engineering information systems)

Semua sistem-sistem informasi tersebut dimaksudkan untuk memberikan informasi

kepada semua tingkatan manajemen, yaitu manajemen tingkat bawah (lower level management), managemen tingkat menengah (middle level management) dan manajemen

tingkat atas (top level management). Sebuah sistem informasi manajemen mengandung elemen-elemen fisik sebagai berikut:

1. Perangkat keras komputer

2. Perangkat lunak: a. Perangkat lunak sistem umum; b. Perangkat lunak terapan umum; c. Program aplikasi

3. Database (data yang tersimpan dalam media penyimpanan komputer)

4. Prosedur

5. Petugas Pengoperasian

\section{Perancangan Sistem Informasi}

Pecancangan sistem adalah sebagai penguraian komponen dengan maksud untuk mengidentifikasi dan mengevaluasi permasalahan-permasalahan, kesempatankesempatan, hambatan-hambatan yang terjadi dan kebutuhan yang diharapkan sehingga dapat diusulkan berbaikanperbaikannya (Mulyanto, 2009:58). Kadir (2013:413) perancangan sistem merupakan bagian penting dalam suatu organisasi untuk memebutuhkan kebutuhan sistem informasi dalam kurung 3 hingga 5 tahun mendatang dan menuangkan ke dalam rencana pengembangan sistem informasi.

\section{Apotek}

Berdasarkan Peraturan Pemerintah No.25 tahun 1980 dan PermenkesNo. 922/MenKes/X/1993, Apotek adalah suatu tempat tertentu dimana dilakukan pekerjaan kefarmasian dan penyaluran obat kepada masyarakat dan 2006 Nomor 1027/MENKES/SK/IX/2004 Standar Pelayanan Kefarmasian Di Apotek

\section{Sistem Inventory (Persediaan barang)}

Sistem Inventory (Persediaan Barang) yang Diajukan, Menurut Ristono (2009) persediaan dapat diartikan sebagai barangbarang yang disimpan untuk digunakan atau dijual pada masa atau periode yang akan datang. Oleh sebab itu dirancang sistem informasi manajemen persediaan barang yang harus diadakan untuk menjamin kelancaran dalam kegiatan pelayanan purna jual, serta menetapkan jadwal pengadaan dan jumlah pemesanan barang sesuai dengan kebutuhan perusahaan. Persediaan yang ada harus seimbang dengan kebutuhan, karena persediaan yang terlalu banyak akan mengakibatkan perusahaan menanggung risiko kerusakan dan biaya penyimpanan 
yang tinggi disamping biaya investasi yang besar serta akan menambah daftar persediaan barang death stock. Tetapi jika terjadi kekurangan persediaan akan berakibat terganggunya kelancaran dalam kegiatan pelayanan purna jual.

\section{METODE PENELITIAN}

Penelitian ini dilakukan pada Apotik Kimia Farma Kota Ternate. Waktu penelitian selama bulan Mei sampai Juli 2016. Penelitian menggunakan data sekunder dan data primer. Data sekunder berupa dokumen kegiatan pengelolaan obat yang diperoleh langsung dari Apotik Kimia Farma Kota Ternate. Sedangkan data primer berupa system informasi manajemen yang diperoleh dari karyawan Kimia Farma melalui observasi dan wawancara.

\section{Analisis dan Pengembangan Sistem}

Analisis system menggunakan Driven Model, dengan pendekatan terstruktur. Sedangkan pengembangan system mengacu pada model Waterfall (Pressman, 2005), terdiri dari 4 tahapan yang saling terkait dan mempengaruhi, yaitu : 1) Analisis system; 2) Perancangan dan Pemodelan Sistem; 3) Implementasi Sistem Implementasi; 4) Pengujian Sistem.

Perancangan terfokus pada aliran data, proses bisnis dan perangkat lunak secara Bottom-up Approach yang disebut proses oriented yaitu pendekatan yang dimulai pada level bawah sampai dengan level atas organisasi, dengan menggambarkan serangkaian proses pada diagram alir data (DAD) yang menggambarkan proses yang berjalan atau diusulkan bersama-sama dengan input, ouput dan file mereka yaitu Diagram Konteks, Data Flow Diagram (DFD) Membuat pemetaan setiap proses sistem tersebut untuk mendefinisikan dengan tepat fungsionalitas yang harus disediakan oleh sistem dan Entity Relationship Diagram (ERD), Rancangan Tabel Database serta Rancangan Layout Sistem.

\section{Analisis Sistem Yang Berjalan}

Sebelum melakukan perancangan system, terlebih dahulu dilakukan analisis system. Analisis system ini bertujuan untuk mengetahui kelemahan-kelemahan system yang sedang berjalan. Adapun alur sistem yang berjalan pada menajemen Persediaan Obat pada kimia farma kota Ternate adalah sebagai berikut:

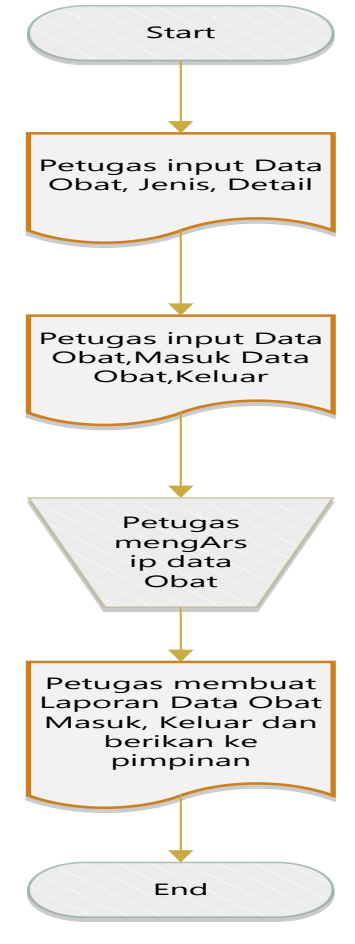

Gambar 1. Sistem yang berjalan

\section{Rancangan System yang Diusulkan}

Berdasarkan kelemahan yang ada pada system berjalan maka dibuat perbaikan untuk meningkatkan system manajemen informasi manajemen persediaan obat pada apotik kimia farma kota Ternate, sebagai berikut 


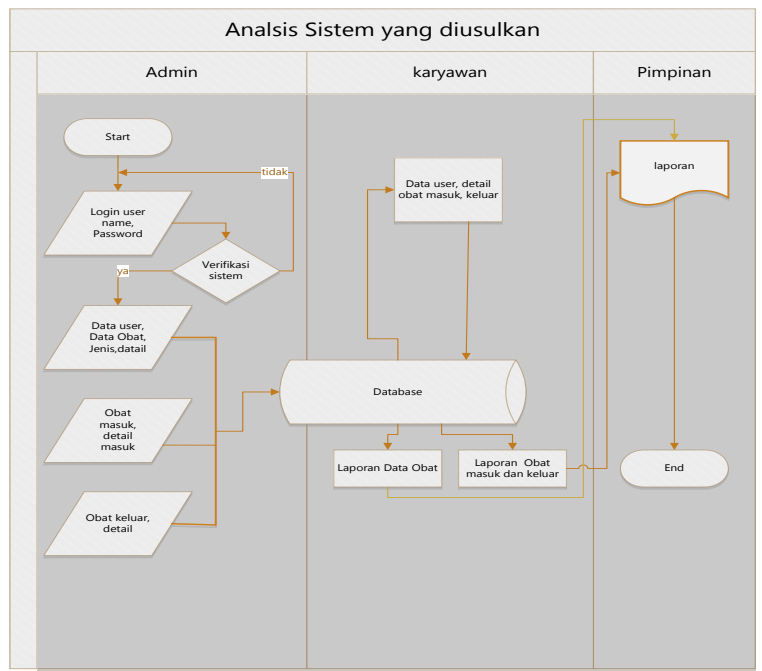

Gambar 2. Sistem Yang Diusulkan

\section{PERANCANGAN SISTEM \\ Perancangan Tabel Database}

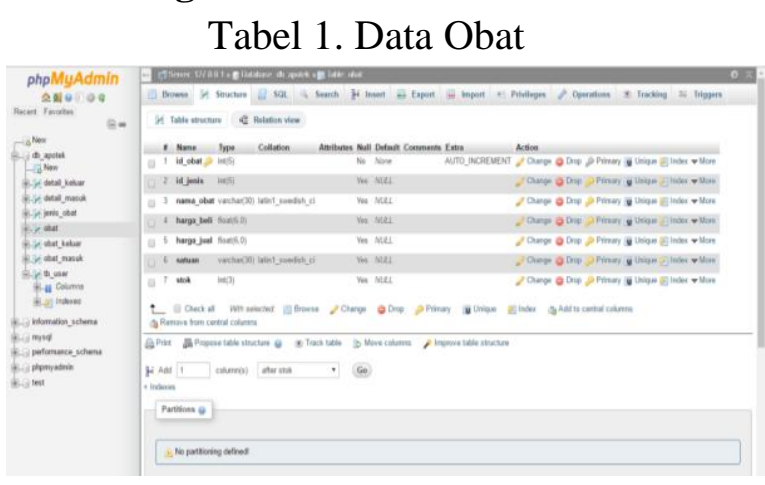

Tabel 2. Jenis Obat

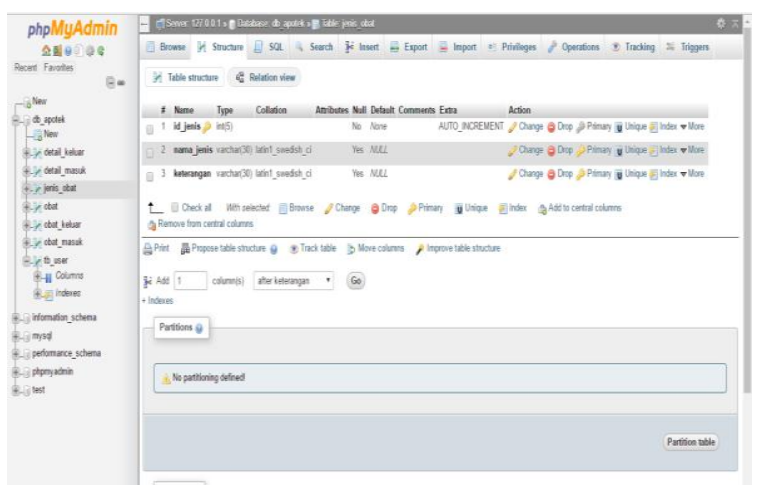

Tabel 3. Obat Masuk

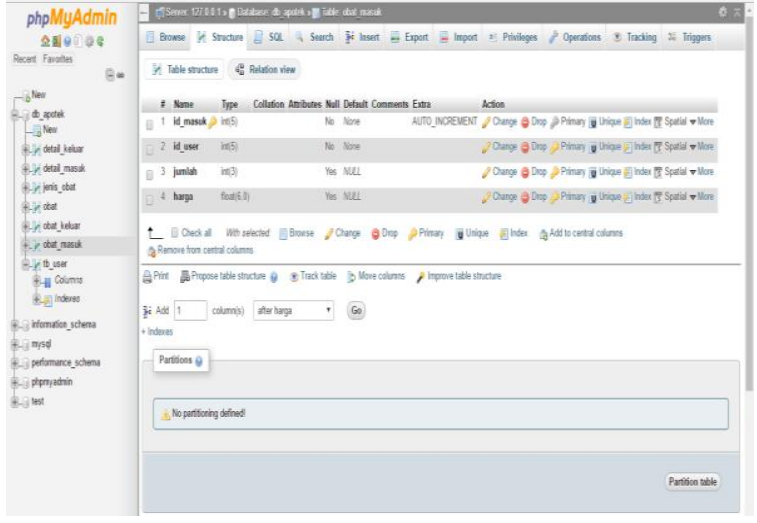

Tabel 4. Obat Keluar

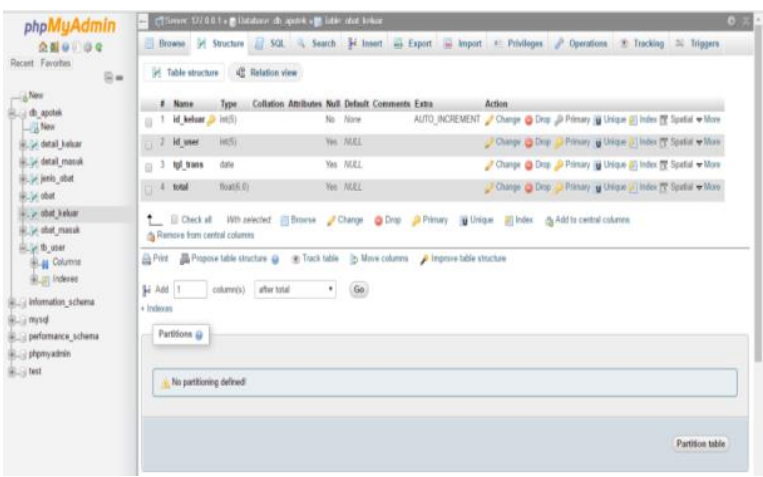

\section{Diagram Konteks}

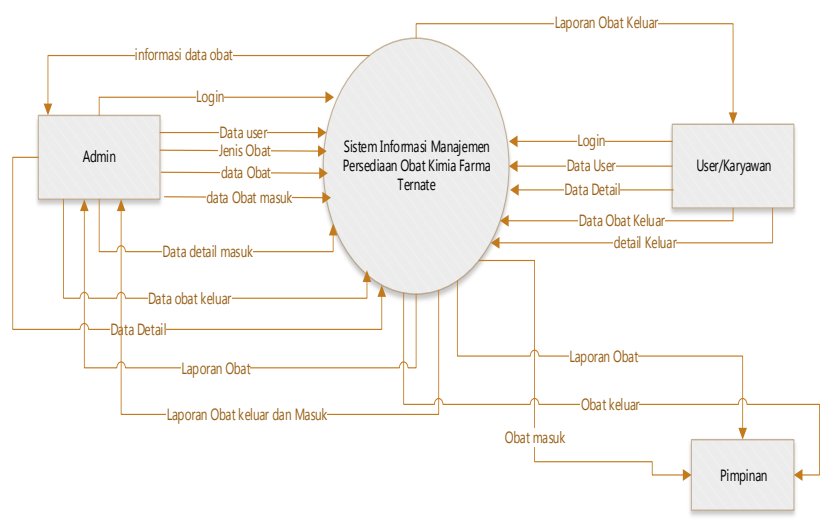

Gambar 3. Diagram Konteks

\section{DFD Level 1}

Diagram Level 1 merupakan diagram uraian dari proses yang ada pada Diagram konteks Berikut merupakan tampilan gambar diagram level 1 pada sistem informasi manajemen obat pada apotek kimia farma. 


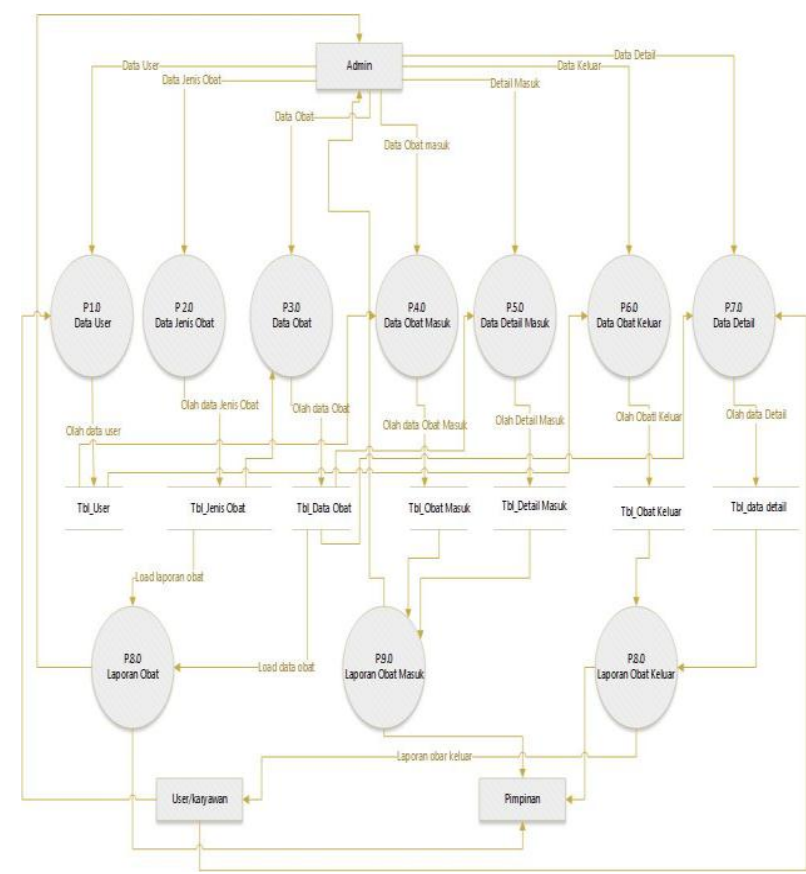

Gambar 4. Diagram Level 0

\section{ERD Relasi Tabel}

Entity Relationship Diagram atau yang biasa disingkat ERD merupakan rancangan model database relasi antar entity dan objek, berikut merupakan hasil rancagan ERD relasi tabel

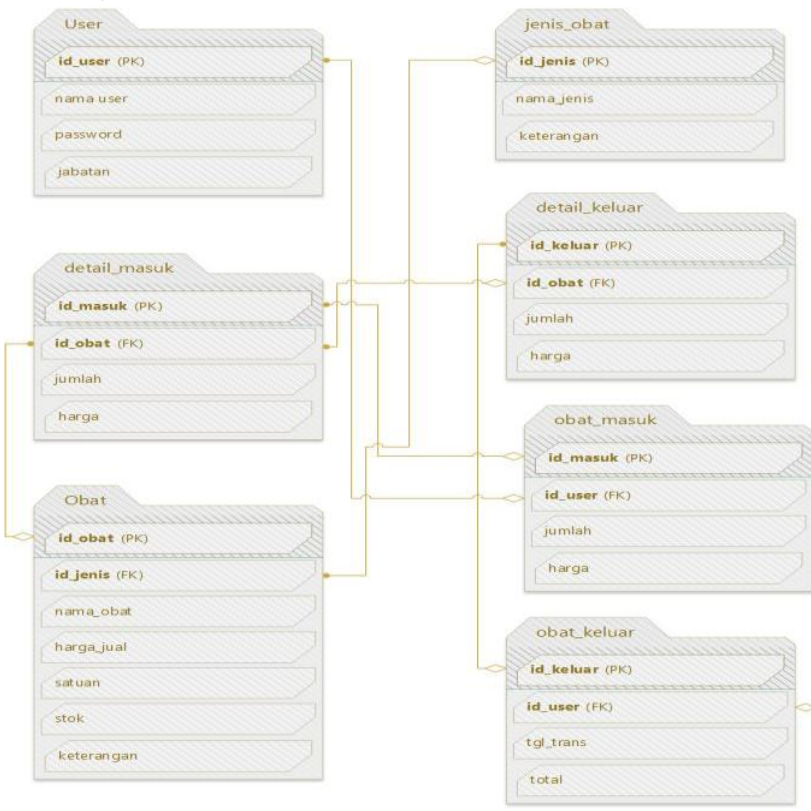

Gambar 5. Relasi Tabel

\section{Entity Relationship Diagram (ERD)}

Notasi

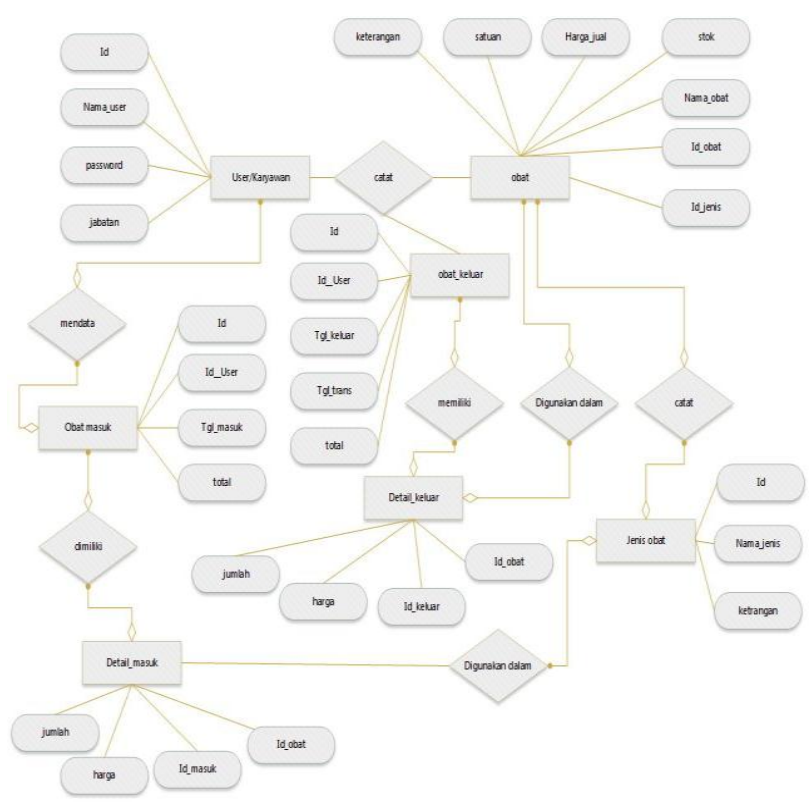

Gambar 6. Erd Notasi

\section{IMPLEMENTASI SISTEM}

Pada tahapan ini merupakan penerapan sistem yang sudah dirancang dan coding sesuai dengan rencana yang ditentukan, Sistem yang diimplementasikan dengan menggunakan data pada Apotik Kimia Farma Ternte, berikut merupakan hasil implementasi Sistem yang sudah di buat

\section{Data User}

Tampilan Data User merupakan tampilan menu pada admin saat melakukan pengeloalaan data user pada sistem untuk menambahkan dan menghapus, berikut adalah tampilan gambar Data User

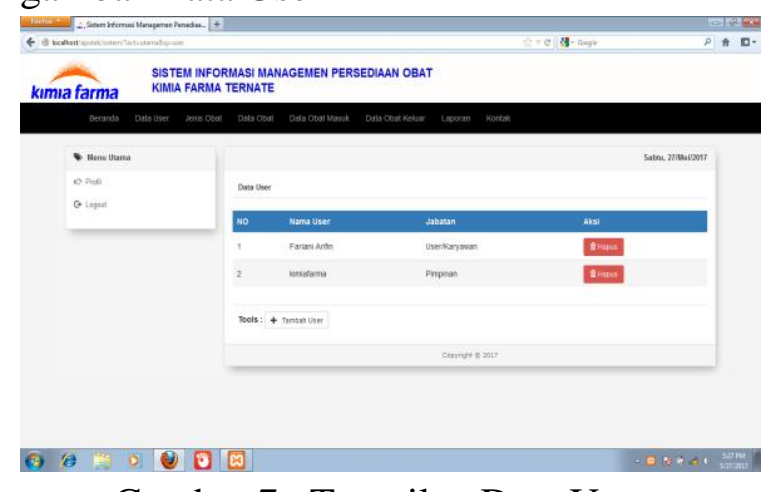

Gambar 7. Tampilan Data User

\section{Halaman Jenis Obat}


Tampilan Jenis Obat merupakan tampilan saat admin, dalam mengelola data Jenis obat diantaranya tambah jenis obat, hapus, simpan dan cari jenis, berikut merupakan tampilan Halaman kelola menu Jenis Obat

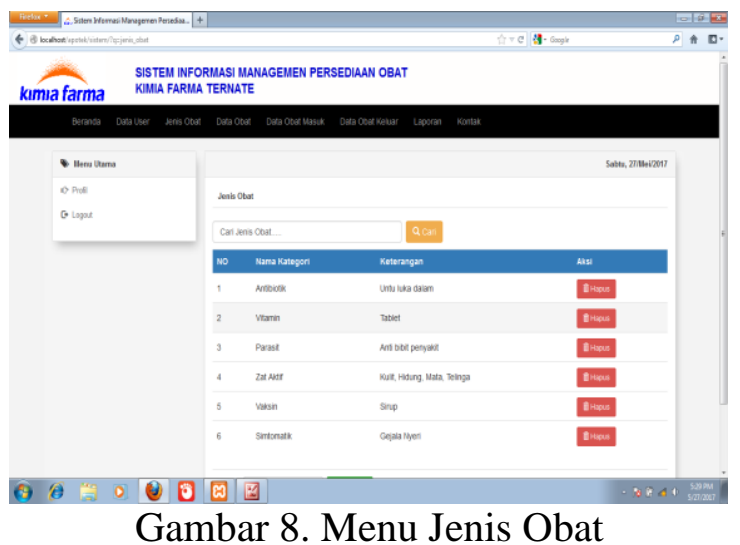

\section{Halaman Menu Data Obat}

Tampilan Halaman Menu Data Obat merupakan tampilan pada Admin dalam mengelola Data Obat pada sistem, dalam pengelolaan Data Obat terdapat beberapa menu kelola diantaranya Tambah, Simpan dan Hapus, berikut merupakan tampilan menu Data Obat

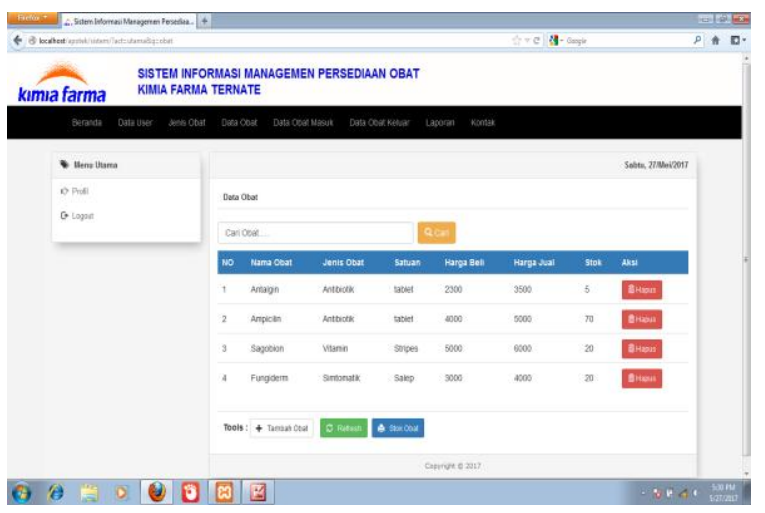

Gambar 9. Menu Data Obat

\section{Halaman Menu Data Obat Masuk}

Tampilan Halaman Menu Data Obat Masuk merupakan tampilan pada Admin dalam Pengelolaan Data Obat masuk pada sistem, berikut merupakan tampilan menu Data Obat Masuk

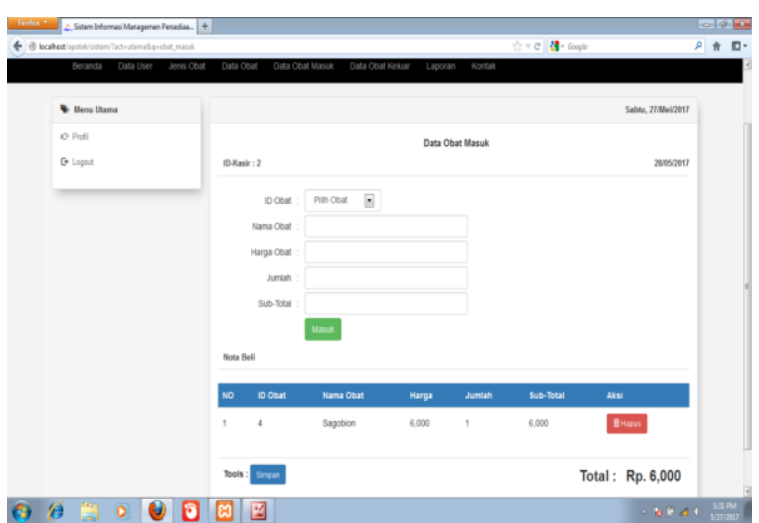

Gambar 10. Menu Data Obat Masuk

\section{Halaman Menu Data Obat Keluar}

Tampilan Halaman Menu Data Obat Keluar merupakan tampilan pada Admin dalam Pengelolaan Data Obat Keluar yang diorder, berikut merupakan tampilan Halaman Data Obat Keluar

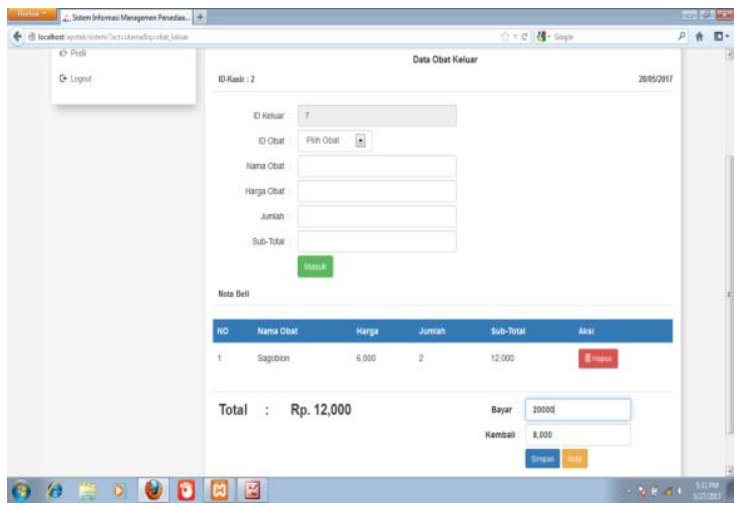

Gambar 11. Menu Data Obat Keluar

\section{Halaman Cetak Laporan Stok}

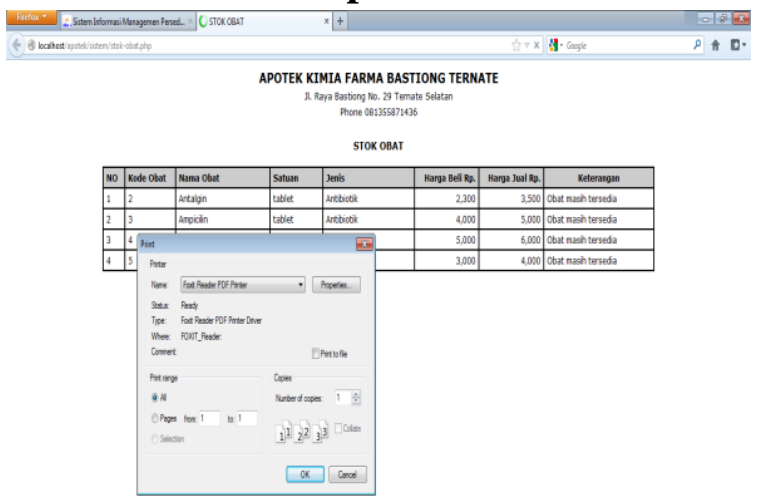

(9)

Gambar 12. Menu Data Obat Keluar 
Berdasarkan uraian yang telah Peneliti jelaskan pada bab-bab terdahulu dan pembuatan Sistem Informasi Persediaan Obat Berbasis Web Pada Apotik Kimia Farma Ternate, maka dapat dimbil kesimpulan sebagai berikut: 1). Sistem ini Mempermudah dan mempercepat proses kerja Admin dan User dalam mengelola data obat dan Transaksi obat pada Apotik Kimia Farma. 2). Mempermudah pemilik untuk melihat laporan secara cepat pada sistem dimana saja, Serta meningkatkan kinerja karyawan dalam proses pembuatan laporan Transaksi dan Data Stok Obat.

Sistem Informasi Persediaan Obat Berbasis Web Pada Apotik Kimia Farma Ternate ini masih bisa dikembangkan seiring dengan perkembangan spesifikasi kebutuhan pengguna sistem yang harus dipenuhi dalam mencapai tahap yang lebih tinggi dan kinerja sistem yang lebih baik. Sebagai saran untuk pengembangan sistem lebih lanjut adalah: 1) Sistem ini memerlukan domain dan hosting mendukung dalam menjalankan Sistem melalui jaringan internet sebagai media agar pemilik dapat mengontrol transaksi dan persediaan dimana saja: 2) Perlu adanya pelatihan pada Admin, User yang menggunakan sistem ini nanti pada Apotik Kimia Farma agar sistem dapat dijalankan secara maksimal.

\section{DAFTAR PUSTAKA}

Pressman, S. Roger. 2005. E-book Software Engineering: a Practitioner's Approach. Seventh Edition.

Keputusan Menteri Kesehatan Republik Indonesia, 2006. Nomor 1027/MENKES/SK/IX/2004, Standard Pelayanan Kefarmasian di Apotek
LeRounge, C., Mantzana, V. Dan Wilson, E.V. 2007. Healthcare Information Systems Research, Revelation and Visions

Pangestu, Danu Wira, 2007. Teori Dasar Sistem Informasi Manajemen (SIM). Ilmu Komputer.Com. at:http://bangdanu.wordpress.com.

Agus Ristono, 2009. Manajemen Persediaan. Graha Ilmu: Yogyakarta

Peraturan Pemerintah No. 51, 2009 Pekerjaan Kefarmasian.

Lestari, Veronica Sri, S. N. Sirajuddin, S.Rohani, M. Aminawar, A. H. Hoddi, 2011. Dasar-Dasar Manajemen. Jurusan Sosial Ekonomi Peternakan Fakultas Peternakan Universitas Hasanuddin.

Sutabri Tata 2012. Analisis Sistem Informasi. Andi Offset: Yogyakarta

Darmawan, Deni, 2013, Sistem Informasi Manajemen. PT Remaja Rosdakarya Offset: Bandung

Deni, Eko Purwanto, 2013. Pembangunan Sistem Informasi Apotek Pink Pacitan. Journal Speed - Sentra Penelitian Engineering dan Edukasi. Volume 5 No 3 2013, ISSN: 1979-9330 (Print) 2088-0154 (Online) ijns.org.

Taufiq,2013. Sistem Informasi Manajemen Konsep Dasar, Analisis dan Metode Pengembangan. Graha Ilmu: Yogyakarta.

Agus Eka Pratama, 2014. Sistem Informasi Implementasinya. Informatika: Bandung.

Kadir, Abdul, 2014. Pengenalan Sistem

Informasi. CV. Andi OFFSET: Yogyakarta

Heryanto Imam, 2014. Pemrograman Website HTML, PHP, dan MySQL. Modula: Bandung 